Check for updates

Cite this: RSC Adv., 2018, 8, 29607

Received 22nd January 2018

Accepted 22nd July 2018

DOI: $10.1039 / \mathrm{c} 8 \mathrm{ra00671g}$

rsc.li/rsc-advances

\section{Synthesis of 2D Zn-Co LDH nanosheets by a successive ionic layer deposition method as a material for electrodes of high-performance alkaline battery-supercapacitor hybrid devices}

\begin{abstract}
A. A. Lobinsky (D) and V. P. Tolstoy (D)
In recent years, increasing attention directed at creating novel two-dimensional graphene-like materials, in particular materials based on oxides or hydroxides of transition metals, as they have a number of unique properties, which determine the perspective of their application in various fields of electronics and electrical engineering, as well as in energy storage devices. In this paper we propose a novel promising route for the synthesis of nanolayer layered double hydroxides on the basis of zinc and cobalt by a successive ionic layer deposition method. The obtained nanolayers were characterized by SEM, EDX, XRD, HRTEM, XPS and FT-IR. The results show the synthesized nanolayers were formed from twodimensional nanocrystals with the thickness of about 6-9 $\mathrm{nm}$ and the morphology of the so-called "nanosheets" with the hydrotalcite-like crystal structure of an LDH. In addition, the obtained nanolayers were investigated as electrode materials for alkaline battery-supercapacitor hybrid devices and demonstrated a high specific capacitance $\left(270 \mathrm{~mA} \mathrm{~h} \mathrm{~g} \mathrm{~g}^{-1}\right.$ at $1 \mathrm{~A} \mathrm{~g}^{-1}$ ) and excellent electrochemical stability (3\% drop in capacity after 1000 charge-discharge cycles).
\end{abstract}

\section{Introduction}

The two-dimensional ultrathin metal oxide and hydroxide nanostructures, such as nanosheets, have received attention in recent years, due to their outstanding properties resulting from their small thickness and large surface area. ${ }^{\mathbf{1 , 2}}$ As a result, metal oxide (hydroxide) nanosheets have shown intriguing and exciting properties for use as ferromagnetic materials, ${ }^{3}$ photodetectors, ${ }^{4}$ photocatalysts, ${ }^{5}$ gas sensors $^{6,7}$ and also as electrode materials for energy storage devices, including supercapacitors $^{\mathbf{8 , 9}}$ and battery ${ }^{\mathbf{1 0 , 1 1}}$ energy storage devices.

The battery-supercapacitor hybrid (BSH) energy storage devices based on a battery electrode and a supercapacitor electrode, offer a promising way to construct devices with merits of both secondary batteries and supercapacitors. ${ }^{\mathbf{1 2}}$ Electric double-layer capacitors (EDLCs) type supercapacitors utilize the electric double layer mechanism to store ions, which enables fast charge carrier kinetics but offers limited capacity. In batteries use electrochemical reactions for storage charge and providing high specific capacity, but this suffer from slow ion transport. ${ }^{\mathbf{1 3 1 4}}$ The most intuitive approach to combine high energy and high power density within a single device is to combine the different types of energy storage sources, namely hybridization between EDLCs and battery

Department of Chemistry, Saint-Petersburg State University, Peterhof, 198504 Saint-Petersburg, Russia.E-mail: lobinsky.a@gmail.com type electrodes. ${ }^{15}$ This hybridization is indispensable to meet with the demands of both higher energy and power densities for powering future multifunctional electronics, hybrid electric vehicles, mobile electronics devices and industrial equipment. ${ }^{16}$

As electrodes for alkaline BSHs employ is carbon materials or electrodes is based on transition metal oxides/hydroxides (Ni, $\mathrm{Co}, \mathrm{Mn}$ and Fe-based)and aqueous alkaline solution used as electrolytes. ${ }^{17}$ The transition metal compounds in basic aqueous electrolytes exhibit high capacity performance, higher than aqueous $\mathrm{Li}$ - or $\mathrm{Na}$-ion battery or supercapacitors electrodes. In last years, many different electrode materials were developed to pursue high energy densities and specific capacitance of alkaline BSHs. ${ }^{12,18}$

In the development of high-performance BSHs, the batterytype electrode materials play a key role. The transition metal oxides are widely used as electroactive materials for alkaline $\mathrm{BSH}$ electrodes, because they provide high values power density, for instance $\mathrm{NiO},{ }^{19} \mathrm{Ni}(\mathrm{OH})_{2},{ }^{20} \mathrm{SnO}_{2},{ }^{21} \mathrm{Fe}_{3} \mathrm{O}_{4},{ }^{18} \mathrm{NiMoO}_{4}$ (ref. 22) and $\mathrm{CoMoO}_{4},{ }^{23} \mathrm{Co}_{3} \mathrm{O}_{4},{ }^{24} \mathrm{Bi}_{2} \mathrm{O}_{3}$ (ref. 25) etc.

The layer double hydroxides (LDHs) nanosheets of transition metals have been demonstrated as prospective candidates for energy storage, in view of their nanoscale thickness high surface area, capability of alleviating the volume change during the charge/discharge process, increased energy density, and also their relatively low cost and environmentally friendly. ${ }^{\mathbf{2 6 , 2 7}}$ Recently, a number of LDHs have been reported as 
electrode materials for $\mathrm{BSH}$ device including $\mathrm{Co}-\mathrm{Al} \mathrm{LDH},{ }^{28} \mathrm{Ni}-$ Al LDH, ${ }^{29} \mathrm{Co}-\mathrm{Mn} \mathrm{LDH},{ }^{30} \mathrm{Zn}-\mathrm{Co} \mathrm{LDH}^{31}$ and $\mathrm{Ni}-\mathrm{Co} \mathrm{LDH}^{32}$ etc.

The LDHs of transition metals with nanosheets morphology usually have been obtained using hydrothermal $^{33,34}$ and solvothermal ${ }^{35}$ method, CBD method, ${ }^{36,37}$ precipitation, $^{38}$ microwave radiation $^{39}$ and electrodeposition. ${ }^{\mathbf{4 0 - 4 2}}$ New possibilities for obtain two-dimensional ultrathin metal oxide and hydroxide open the synthesis by Successive Ionic Layer Deposition (SILD) method, also called the Successive Ionic Layer Adsorption and Reaction (SILAR). ${ }^{43}$ This method is based on multiple and successive treatment of substrate by solutions of reagents which enter into reaction at its surface and form a layer of poorly soluble substance that makes possible to deposit nanolayers of controlled thickness on the surface of parts of any shape, which are exactly the requirements to the methods of synthesis of the nanolayers on the surface of electrodes for supercapacitors or batteries and to be used previously for the synthesis of nanolayers of oxides, ${ }^{44}$ fluorides, ${ }^{45}$ and also noble metal nanoparticles. ${ }^{\mathbf{4 6 , 4 7}}$ Earlier, we published the work ${ }^{48}$ in which was shown obtaining by SILD method of electrodes for supercapacitor based on the nickel oxide nanolayers with the morphology of nanosheets, which demonstrated high electrochemical stability and specific capacitance. Also of this method was used for obtaining electrode materials for aqueous batteries and supercapacitors based on $\mathrm{LDH} \mathrm{Ni}_{2} \mathrm{Al}(\mathrm{OH})_{7-2 x}\left(\mathrm{CO}_{3}\right)_{x} \cdot n \mathrm{H}_{2} \mathrm{O}^{49}$ and $\mathrm{LDH} \mathrm{Co}_{2} \mathrm{Al}(\mathrm{OH})_{7-2 x}\left(\mathrm{CO}_{3}\right)_{x} \cdot n \mathrm{H}_{2} \mathrm{O},{ }^{50}$ respectively, allowed to achieve relatively high values of specific capacitance. In this work, we present a novel synthetic route by SILD method to prepare ultrathin $2 \mathrm{D} \mathrm{Zn}-\mathrm{Co} \mathrm{LDH}$ nanosheets and investigation their electrochemical properties as battery-type electrode material for alkaline BSH devices.

\section{Experimental}

\section{Preparation of the reagents}

The single-crystal silicon wafers with $\langle 100\rangle$ orientation and size $10 \times 20 \times 0.35 \mathrm{~mm}$, and polycrystalline nickel foam (NF) plates (porosity $110 \mathrm{PPI}$, size $5 \times 30 \mathrm{~mm}$, trademark AO (JSC) ECAT) were used as substrate for synthesis and carried out physical characterization and electrochemical experiments, respectively. Silicon wafers were cleaned in an ultrasonic bath filled with acetone for 10 minutes. Afterward, plates were sequentially treated for 10 minutes in concentrated HF, then washed with deionized water for several times and further in $0.1 \mathrm{M} \mathrm{KOH}$ and again washed water. NF plates were treated according to the technique described in $^{48}$ for 15 minutes in $6 \mathrm{M} \mathrm{HCl}$ solution, then several times rinsed by water and dried on air at $120^{\circ} \mathrm{C}$ for $30 \mathrm{~min}$.

For the synthesis of nanolayers as precursors were used aqueous solution of cobalt acetate $(C=0.01 \mathrm{M})$ and also aqueous solution of mixed salts zinc sulfate and potassium persulfate as oxidizer. The last solution $(\mathrm{pH}=12)$ was prepared by dissolving dry analytical grade salts $\mathrm{ZnSO}_{4}(C=0.01 \mathrm{M})$ and $\mathrm{K}_{2} \mathrm{~S}_{2} \mathrm{O}_{8}(C=0.01 \mathrm{M})$ in deionized water. The $\mathrm{pH}$ value of the solution was achieved by the addition of $1 \mathrm{M} \mathrm{KOH}$.

\section{Synthesis of 2D Zn-Co LDH nanolayers}

On first step of SILD synthesis the substrate plates were immersed into solution of cobalt acetate (I) and then washed from excess reagent in distilled water (II). On the second step, plates were immersed in solution of mixture zinc sulfate and potassium persulfate (oxidizer) with (III), and again washed in water (IV) (Fig. 1). This sequence corresponds to one SILD cycle, which is repeated 30 times to obtain desired film thickness. The time of treatment in solutions of reagents and in washing in water was $30 \mathrm{~s}$. The synthesis was carried out at room temperature and atmospheric pressure. Finished the sample was calcined on air at $150{ }^{\circ} \mathrm{C}$ for 30 minutes at a heating rate of $5{ }^{\circ} \mathrm{C} \min ^{-1}$.

\section{Material characterization}

The morphology and compositional analyses of the samples were characterized by scanning electron microscope (SEM) at accelerating voltage $4 \mathrm{kV}$ on Zeiss Merlin microscope and energy-dispersive X-ray spectroscopy (EDX) used detector Oxford INCA 350, and also XPS used ESCALAB 250Xi electron spectrometer, with $\mathrm{Al} \mathrm{K} \alpha$ radiation (14 $866 \mathrm{eV}$ ). X-ray diffraction (XRD) patterns were recorded using a diffractometer RigakuMiniflex II with a Co $\mathrm{K} \alpha$ radiation $(\lambda=0,179026 \mathrm{~nm})$. Highresolution transmission electron microscopy (HRTEM) (Zeiss Libra $200 \mathrm{FE}, 200 \mathrm{kV}$ ) are applied to evaluate the morphologies and microstructures of the prepared samples. The structural characterization was carried out by using FTIR spectroscopy

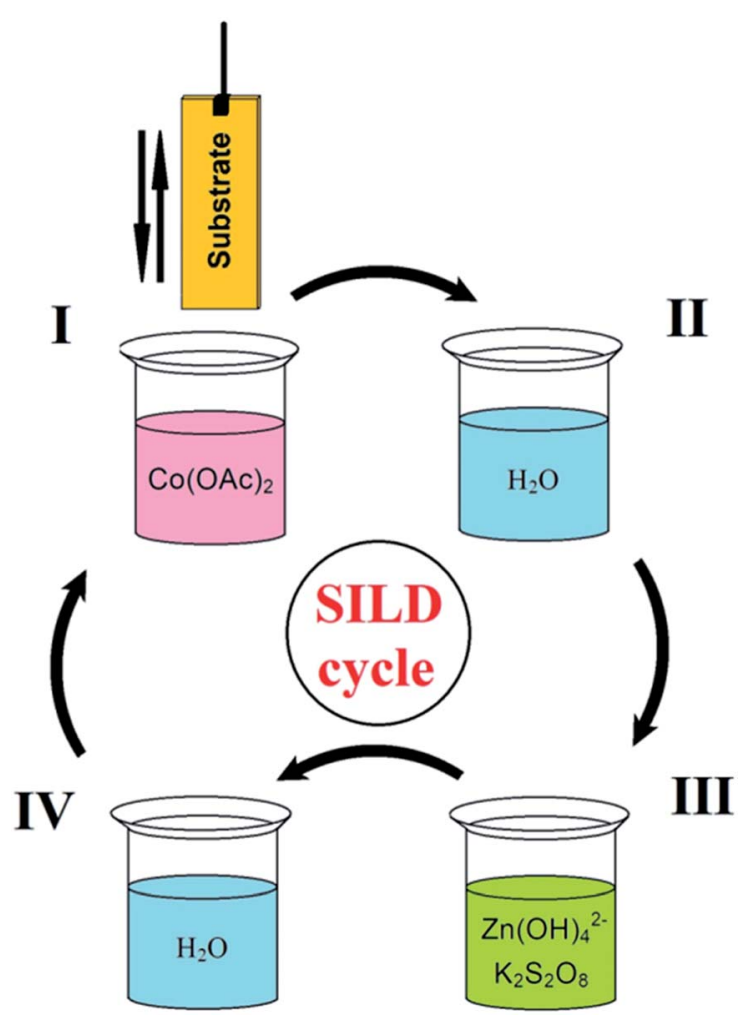

Fig. 1 Schematic presentation of SILD technique for production of $\mathrm{Zn}-\mathrm{Co} \mathrm{LDH}$ nanolayers. 
(FCM 2201 spectrophotometer) using differential technique with respect to spectra of bare silicon plate.

\section{Electrochemical measurements}

The electrochemical measurements of the samples was tested on a Elins P-30I potentiostat with cyclic voltammetry and galvanostatic charge-discharge functions using a three-electrode cell where platinum foil serves as the counter electrode and a $\mathrm{Ag} / \mathrm{AgCl}$ (aq. $\mathrm{KCl}$ sat.) as the reference electrode. The working electrode was prepared by deposition $\mathrm{Zn}-\mathrm{Co} \mathrm{LDH}$ nanolayers on Ni foam surface as result 30 treatment cycles by SILD method. The specific capacitance $C\left(\mathrm{~mA} \mathrm{~h} \mathrm{~g}^{-1}\right)$ at different current densities can be calculated via eqn (1): ${ }^{49}$

$$
C=\left(\int I \mathrm{~d} t\right) / m,
$$

where $I(\mathrm{~mA})$ is a galvanostatic current, $\Delta t(\mathrm{~h})$ is the discharge time of a cycle and $m(\mathrm{~g})$ is the mass of the active material in the film electrode. The loading mass of active material on nickel foam $(1.8 \mathrm{mg}$ ) was measured by weight difference method using OHAUS Pioneer ${ }^{\text {TM} P A 54 C ~ p r e c i s e ~ b a l a n c e . ~}$

\section{Results and discussion}

The morphology of samples was characterized by SEM method (Fig. 2). It can be seen that the nanolayers formed by twodimensional nanocrystals with sheet-like morphology with thickness of about 6-9 $\mathrm{nm}$ and they were mainly vertically grown on the substrate surface. As can be seen from the Fig. 2, the morphology of the nanolayers varies insignificantly as a result of carried out charge-discharge cycles.

The chemical composition and chemical state of the elements in the nanolayer were identified by energy dispersive X-ray spectroscopy (EDX) and X-ray photoelectron spectroscopy (XPS). The EDX spectrum shown in Fig. 3(a) indicates the presence of $\mathrm{Zn}$ and Co elements with the atomic ration 1.0 and 0.9 , respectively, which is coincident of the survey spectrum of XPS (Fig. 3(b)). Average content of $\mathrm{K}$ and $\mathrm{S}$ in nanolayer was no more than few percent. As shown in Fig. 3(c), two major peaks with binding energy $780.6 \mathrm{eV}$ and $795.7 \mathrm{eV}$ are corresponding to Co $2 \mathrm{p}_{1 / 2}$ and Co $2 \mathrm{p}_{3 / 2}$, indicating that element Co is the
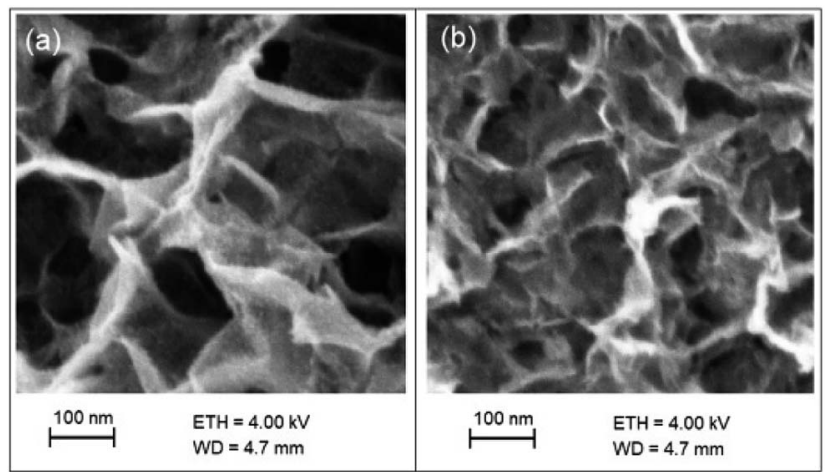

Fig. 2 SEM images of $\mathrm{Zn}-\mathrm{Co}$ LDH nanolayers before (a) and after 1000 charge-discharge cycles (b).
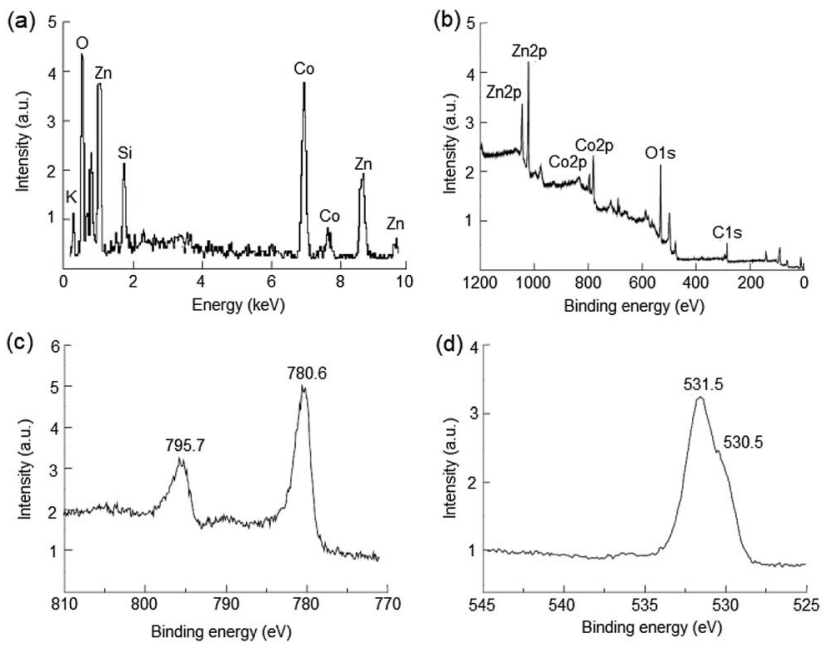

Fig. 3 EDX spectrum (a) and XPS survey spectrum (b), high-resolution spectra of Co 2p (c) and O 1s (d) of Zn-Co LDH nanolayers synthesized by the SILD method.

chemical state of $3+$ in the sample. ${ }^{51}$ The $\mathrm{O} 1$ s spectra (Fig. 3(d)) reveal the presence bands of hydroxide $(530.5 \mathrm{eV})$ and water molecules $(531.5 \mathrm{eV}) .^{52}$

The crystal structure of synthesized nanolayers was investigated by XRD. The XRD patterns (Fig. 4) of the synthesized nanolayers show characteristic reflections crystal planes (012), (015), (018), (110) and (113) which can be corresponding to a layered hydrotalcite-like phase of $\mathrm{LDH} .^{53,54}$

Fig. 5 shows the FT-IR spectra of synthesized sample. The signal at $3380 \mathrm{~cm}^{-1}$ is the $\mathrm{O}-\mathrm{H}$ stretching band from water molecules. ${ }^{55}$ The band at $2950 \mathrm{~cm}^{-1}$ can were attributed the stretching vibrations of bonds $\mathrm{C}-\mathrm{H},{ }^{55}$ and absorption bands at 1480 and $1390 \mathrm{~cm}^{-1}$ - to the $\mathrm{C}=\mathrm{O}$ vibration bond of acetate anions. ${ }^{55}$ The band at $1115 \mathrm{~cm}^{-1}$ and the broad peak at $575 \mathrm{~cm}^{-1}$ can be assigned to the vibration bond of $\mathrm{SO}_{4}{ }^{2-}$ anions in nanolayer. ${ }^{56}$

The HRTEM image (Fig. 6) reveals the polycrystalline structure of nanolayers with nanosheets morphology synthesized by

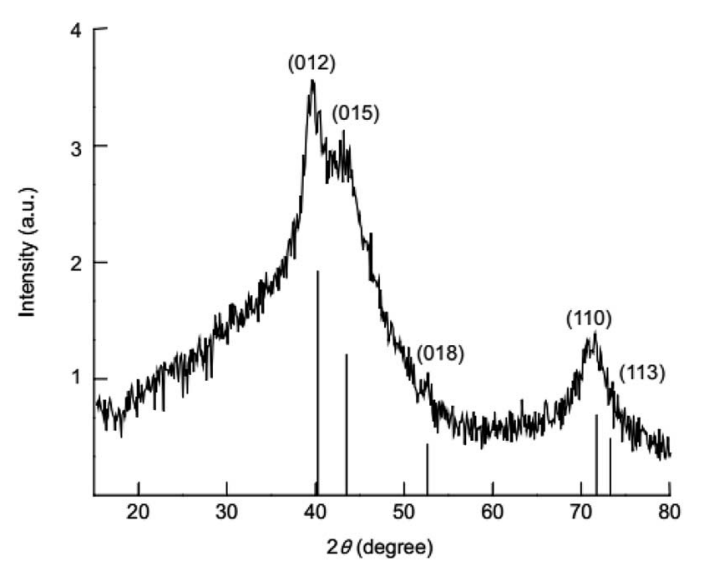

Fig. 4 XRD pattern of Zn-Co LDH nanolayers synthesized by the SILD method. 


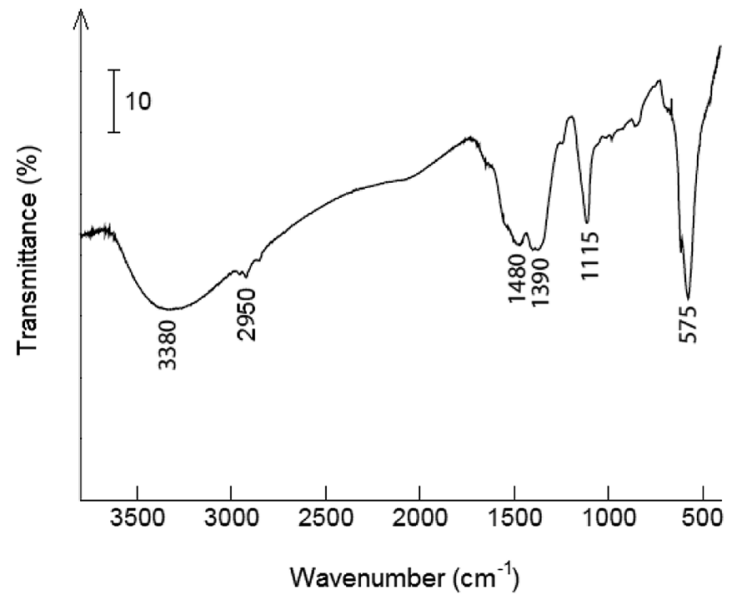

Fig. 5 FT-IR spectrum of Zn-Co LDH nanolayers synthesized by the SILD method.

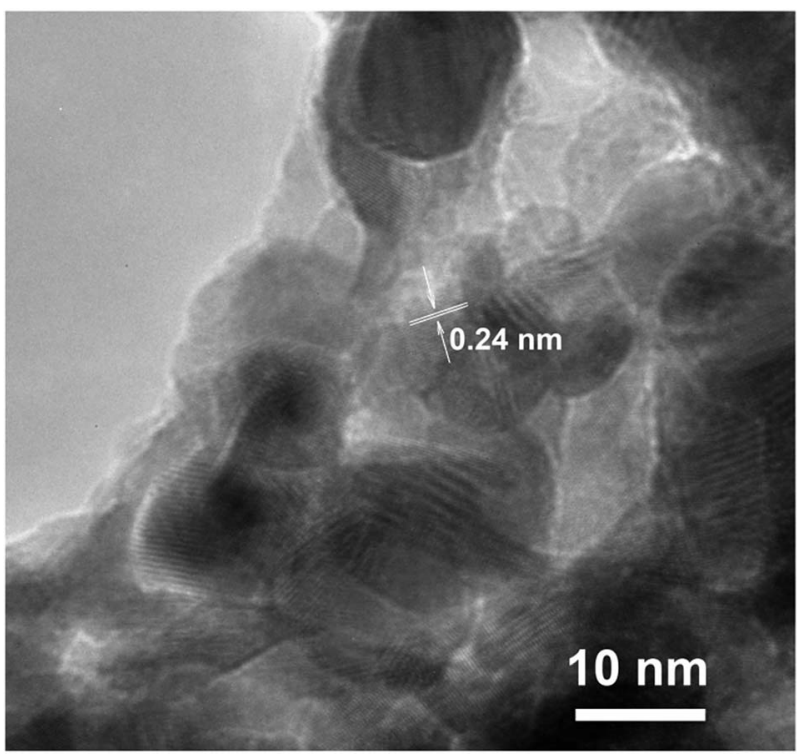

Fig. 6 TEM image of $\mathrm{Zn}-\mathrm{Co}$ LDH nanolayers synthesized by the SILD method.

SILD method. The clearly resolved lattice fringes show that the $d$-spacing of $0.24 \mathrm{~nm}$ marked in the pattern could be indexed to the (012) crystal planes of the ZnCo-LDH phase, which well agreed with the result of XRD data.

The based on result of XRD, HRTEM, FT-IR, EDX and XPS methods the chemical formula of the prepared product was briefly determined as $\mathrm{Zn}-\mathrm{Co} \mathrm{LDH}$.

The scheme of the chemical processes occurring on the surface at SILD synthesis was illustrated in Fig. 7. At the first step after dipping in the solution of $\mathrm{Co}(\mathrm{OAc})_{2}$ on the surface adsorption occurs of cations of $\mathrm{Co}^{2+} \mathrm{aq}$ (2). Then substrate treatment in excess solution of mixture $\mathrm{ZnSO}_{4}$ and $\mathrm{K}_{2} \mathrm{~S}_{2} \mathrm{O}_{8}$ salts. At $\mathrm{pH} 12$ zinc exists in solution mainly in form of $\left[\mathrm{Zn}(\mathrm{OH})_{4}\right]^{2-}$ complex. The cations of cobalt(II) oxidized to cobalt(III) as result occurring redox reaction with $\mathrm{K}_{2} \mathrm{~S}_{2} \mathrm{O}_{8}$. Finally, cations of

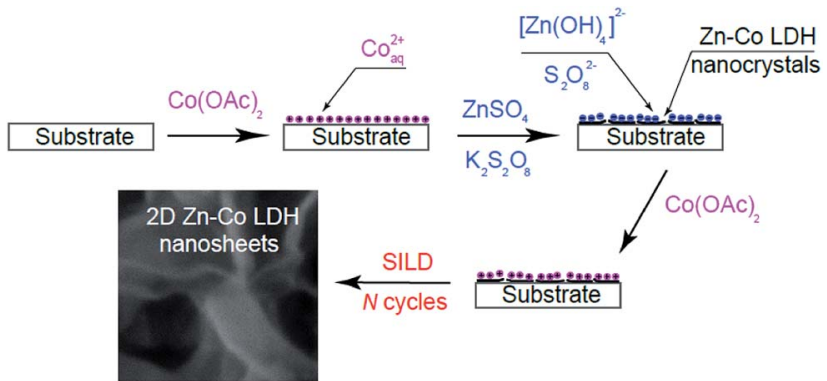

Fig. 7 Schematic illustration of the process formation of nanocrystals $\mathrm{Zn}-\mathrm{Co} \mathrm{LDH}$ with nanosheets morphology on the substrate surface.

cobalt(III) react with complex $\left[\mathrm{Zn}(\mathrm{OH})_{4}\right]^{2-}$ and form $\mathrm{Zn}-\mathrm{Co} \mathrm{LDH}$ (3):

$$
\begin{aligned}
-\mathrm{Ni}-\mathrm{OH}+\mathrm{Co}(\mathrm{OAc})_{2}+\mathrm{H}_{2} \mathrm{O} \rightarrow-\mathrm{NiOCoOH}+2 \mathrm{HOAc} \\
-\mathrm{NiOCoOH}+\mathrm{S}_{2} \mathrm{O}_{8}{ }^{2-}+\left[\mathrm{Zn}(\mathrm{OH})_{4}\right]^{2-} \\
+\mathrm{H}_{2} \mathrm{O} \rightarrow-\mathrm{NiOZnCo}(\mathrm{OH})_{4}+2 \mathrm{HSO}_{4}^{-}
\end{aligned}
$$

It is obvious that acetate and sulfate anions also can be included in the composition of the nanolayer when treatment in solutions of the precursors as evidenced by FT-IR spectra. After treatment in the solution of $\mathrm{Co}(\mathrm{OAc})_{2}$ on the second SILD cycle surface of nanocrystals a positive charge is gained and for account of the mutual repulsion are mainly oriented vertically to the substrate surface to formation so-called $2 \mathrm{D}$ "nanosheets". The distortion of the planar geometry of nanocrystals can also occur during treatment in solution of mixture $\mathrm{ZnSO}_{4}$ and $\mathrm{K}_{2} \mathrm{~S}_{2} \mathrm{O}_{8}$ salts.

The electrochemical performance of electrode for alkaline $\mathrm{BSH}$ based on $\mathrm{Zn}$-Co LDHnanosheets grown directly on $\mathrm{Ni}$ foam have been examined in a three-electrode configuration using $1 \mathrm{M} \mathrm{KOH}$ aqueous solution by cyclic voltammetry (CVA) and galvanostatic charge-discharge (CD).

The cyclic voltammograms of the $\mathrm{Zn}-\mathrm{Co} \mathrm{LDH}$ NF electrode were recorded in potential window from 0 to $600 \mathrm{mV} v \mathrm{sg}$ / $\mathrm{AgCl}$ electrode at scanning rates of 5, 10 and $15 \mathrm{mV} \mathrm{s}^{-1}$ (Fig. 8a). The CVA curves show two strong redox peaks in which the anodic peak is due to the oxidation of $\mathrm{Co}^{2+}$ to $\mathrm{Co}^{3+}$ (from 450 to $530 \mathrm{mV}$ ) and cathodic peak is for the reverse process (150-215 mV). ${ }^{57}$ The specific capacitance of the $\mathrm{Zn}-\mathrm{Co}$ LDH NF electrode is calculated from charge-discharge curves (Fig. 8b) by eqn (1) and to be $270 \mathrm{~mA} \mathrm{~h} \mathrm{~g}^{-1}, 125 \mathrm{~mA} \mathrm{~h} \mathrm{~g}^{-1}$ and $42 \mathrm{~mA} \mathrm{~h} \mathrm{~g}{ }^{-1}$ at the current densities of 1,2 and $5 \mathrm{~A} \mathrm{~g}^{-1}$, respectively.

The capacity retention of Zn-Co LDH NF electrode after 1000 charge-discharge cycles at current density $5 \mathrm{~A} \mathrm{~g}^{-1}$ was kept $97 \%$ of its initial capacity (Fig. 9) that show excellent cycling stability of this material. High cycling stability can be explain "nanosheets" morphology of ultrathin nanocrystals of Zn-Co LDH which provide fast diffusion of ions on electrode surface and while not being destruction. 

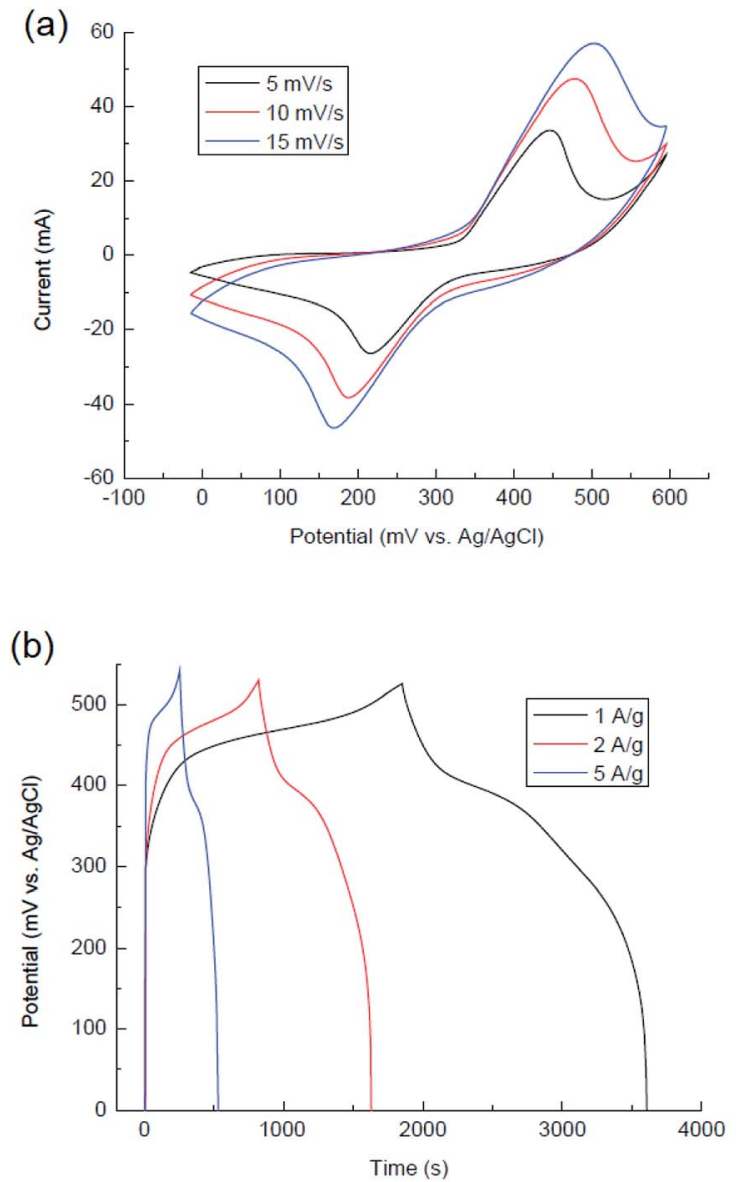

Fig. 8 CVA curves of the $\mathrm{Zn}-\mathrm{Co}$ LDH NF electrode at different scan rates (a) and charge-discharge curves of the $\mathrm{Zn}-\mathrm{Co}$ LDH NF electrode at different current densities (b).

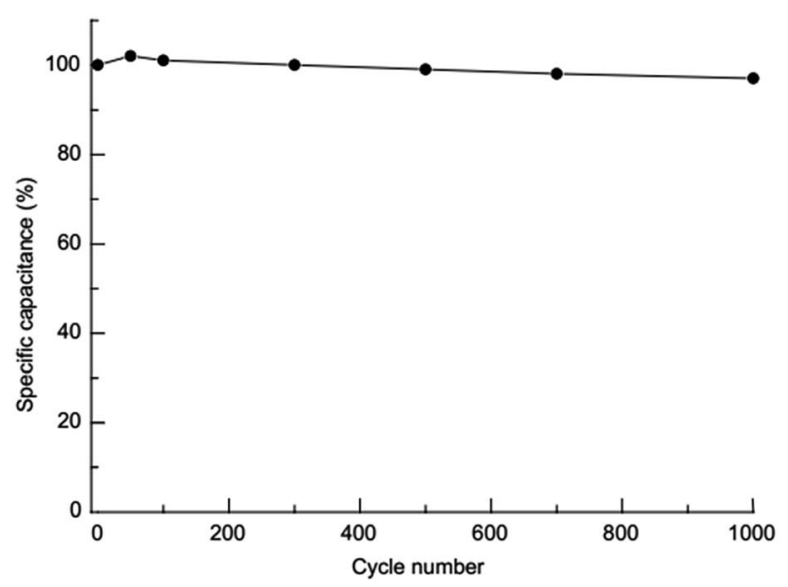

Fig. 9 The cycling stability at $5 \mathrm{~A} \mathrm{~g}^{-1}$ for the $\mathrm{Zn}-\mathrm{Co}$ LDH NF electrode.

\section{Conclusions}

In summary, we propose a novel promising route for the synthesis of nanolayers $\mathrm{Zn}$-Co layered double hydroxides with nanosheets morphology by successive ionic layer deposition method. Obtained nanolayers exhibited good capacitance and electrochemical stability properties to be used as the electrode for alkaline BSH devices. The results show that the obtained $\mathrm{Zn}-$ Co LDH nanolayers exhibited high specific capacity of $270 \mathrm{~mA} \mathrm{~h} \mathrm{~g}^{-1}$ at a current density of $1 \mathrm{~A} \mathrm{~g}^{-1}$ and excellent cycling stability (97\% after 1000 charge-discharge cycles) that allows their used as an electrode material for high-performance BSH devices. We believe this novel method can be extended to prepare other ultrathin 2D materials, in particular for application in charge storage devices.

\section{Conflicts of interest}

There are no conflicts to declare.

\section{Acknowledgements}

The authors gratefully acknowledge to the Centers for X-ray diffraction studies, PMSI and nanotechnology of St. Petersburg State University. We are also grateful to Dr Sc O. V. Levin for useful advice in carrying out of electrochemical measurements.

\section{Notes and references}

1 R. Ma and T. Sasaki, Adv. Mater., 2010, 22, 5082-5104.

2 M. Osada and T. Sasaki, J. Mater. Chem., 2009, 19, 2503-2511.

3 P. Chen, K. Xu, X. Li, Y. Guo, D. Zhou, J. Zhao, X. Wu, C. Wu and Y. Xie, Chem. Sci., 2014, 5, 2251-2255.

4 J. Yang, Y.-L. Jiang, L.-J. Li, E. Muhirea and M.-Z. Gao, Nanoscale, 2016, 8, 8170-8177.

5 K. R. Reyes-Gil, E. A. Reyes-García and D. Raftery, J. Phys. Chem. C, 2007, 111, 14579-14588.

6 H. Yu, T. Yang, R. Zhao, B. Xiao, Z. Li and M. Zhang, RSC Adv., 2015, 5, 104574-104581.

7 L. Yin, D. Chen, X. Cui, L. Ge, J. Yang, L. Yu, B. Zhang, R. Zhang and G. Shao, Nanoscale, 2016, 6, 13690-13700.

8 F. Deng, L. Yu, G. Cheng, T. Lin, M. Sun, F. Ye and Y. Li, J. Power Sources, 2014, 251, 202-207.

9 X. Hu, S. Liu, C. Li, J. Huang, J. Luv, P. Xu, J. Liu and X.-Z. You, Nanoscale, 2016, 8, 11797-11802.

10 T. Tao, Y. Chen, Y. Chen, D. S. Fox, H. Zhang, M. Zhou, M. Raveggi, A. J. Barlow and A. M. Glushenkov, ChemPlusChem, 2017, 82, 295-302.

11 T. Tao, A. M. Glushenkov, C. Zhang, H. Zhang, D. Zhou, Z. Guo, H. K. Liu, Q. Chen, H. Hu and Y. Chen, J. Mater. Chem., 2011, 21, 9350-9355.

12 W. Zuo, R. Li, C. Zhou, Y. Li, J. Xia and J. Liu, Adv. Sci., 2017, 4, 1600539.

13 P. Simon and Y. Gogotsi, Nat. Mater., 2008, 7, 845-854.

14 L. Zhu, H.-J. Peng, J. Liang, J.-Q. Huang, C.-M. Chen, X. Guo, W. Zhu, P. Li and Q. Zhang, Nano Energy, 2015, 11, 746-755.

15 F. Zhang, T. Zhang, X. Yang, L. Zhang, K. Leng, Y. Huang and Y. Chen, Energy Environ. Sci., 2013, 6, 1623-1632.

16 R. T. Wang, J. W. Lang, P. Zhang, Z. Y. Lin and X. B. Yan, Adv. Funct. Mater., 2015, 25, 2270-2278. 
17 Y. Jiao, J. Pei, C. Yan, D. Chen, Y. Hu and G. Chen, J. Mater. Chem. A, 2016, 4, 13344-13351.

18 R. Li, Y. Wang, C. Zhou, C. Wang, X. Ba, Y. Li, X. Huang and J. Liu, Adv. Funct. Mater., 2015, 25, 5384-5394.

19 M. S. Kolathodi, M. Palei and T. S. Natarajan, J. Mater. Chem. A, 2015, 3, 7513-7522.

20 J. Yan, Z. Fan, W. Sun, G. Ning, T. Wei, Q. Zhang, R. Zhang, L. Zhi and F. Wei, Adv. Funct. Mater., 2012, 22, 2632-2641.

21 I. Sultana, T. Ramireddy, M. M. Rahman, Y. Chen and A. M. Glushenkov, Chem. Commun., 2016, 52, 9279-9282.

22 S. Peng, L. Li, H. B. Wu, S. Madhavi and X. W. D. Lou, Adv. Energy Mater., 2015, 5, 1401172.

23 X. Z. Yu, B. G. Lu and Z. Xu, Adv. Mater., 2014, 26, 1044-1051.

24 S. Sun, X. Zhao, M. Yang, L. Wu, Z. Wen and X. Shen, Sci. Rep., 2016, 6, 19564, DOI: 10.1038/srep19564.

25 W. Zuo, W. Zhu, D. Zhao, Y. Sun, Y. Li, J. Liu and X. W. Lou, Energy Environ. Sci., 2016, 9, 2881-2891.

26 G. P. Wang, L. Zhang and J. J. Zhang, Chem. Soc. Rev., 2012, 41, 797-828.

27 L. Zhang, K. N. Hui, K. S. Hui and H. Lee, J. Power Sources, 2016, 318, 76-85.

28 T. M. Masikhwa, M. J. Madito, D. Y. Momodu, J. K. Dangbegnon, O. Guellati, A. Harat, M. Guerioune, F. Barzegar and N. Manyala, RSC Adv., 2016, 6, 46723-46732.

29 M. Liu, S. He, Y.-E. Miao, Y. Huang, H. Lu, L. Zhang and T. Liu, RSC Adv., 2015, 5, 55109-55118.

30 F. O. Ochai-Ejeh, M. J. Madito, D. Y. Momodu, A. A. Khaleed, O. Olaniyan and N. Manyala, Electrochim. Acta, 2017, 252, 41-54.

31 M. A. Woo, M.-S. Song, T. W. Kim, I. Y. Kim, J.-Y. Ju, Y. S. Lee, S. J. Kim, J.-H. Choya and S.-J. Hwang, J. Mater. Chem., 2011, 21, 4286-4292.

32 X. Zheng, Z. Gu, Q. Hu, B. Geng and X. Zhang, RSC Adv., 2015, 5, 17007-17013.

33 W. Ma, R. Ma, J. Wu, P. Sun, X. Liu, K. Zhou and T. Sasaki, Nanoscale, 2016, 8, 10425-10432.

34 Y. Tang, R. Wang, Y. Yang, D. Yan and X. Xiang, ACS Appl. Mater. Interfaces, 2016, 8, 19446-19455.

35 Y. Wei, X. Zhang, X. Wu, D. Tang, K. Cai and Q. Zhang, RSC Adv., 2016, 6, 39317-39322.

36 G. Jia, Y. Hu, Q. Qian, Y. Yao, S. Zhang, Z. Li and Z. Zou, ACS Appl. Mater. Interfaces, 2016, 8(23), 14527-14534.

37 Y. Liu, T. Yu, R. Cai, Y. Li, W. Yang and J. Caro, RSC Adv., 2015, 5, 29552-29557.
38 S. Xu, H.-Y. Zeng, C.-R. Cheng, H.-Z. Duan, J. Han, P.-X. Ding and G.-F. Xiao, RSC Adv., 2015, 5, 71278-71286.

39 S. P. Lonkar, J.-M. Raquez and P. Dubois, Nano-Micro Lett., 2015, 7, 322, DOI: 10.1007/s40820-015-0047-3.

40 Y. Li, L. Zhang, X. Xiang, D. Yan and F. Li, J. Mater. Chem. A, 2014, 2, 13250-13258.

41 Y. Tang, X. Fang, X. Zhang, G. Fernandes, Y. Yan, D. Yan, X. Xiang and J. He, ACS Appl. Mater. Interfaces, 2017, 9, 36762-36771.

42 M. S. Yarger, E. M. P. Steinmiller and K.-S. Choi, Inorg. Chem., 2008, 47(13), 5859-5865.

43 S. S. Ermakov, K. G. Nikolaev and V. P. Tolstoy, Russ. Chem. Rev., 2016, 85(8), 880-900.

44 V. P. Tolstoy, L. B. Gulina, G. S. Korotchenkov and V. I. Brynsari, Appl. Surf. Sci., 2004, 221(1-4), 197-202.

45 V. P. Tolstoy and B. Altangerel, Mater. Lett., 2007, 61(1), 123125.

46 G. Korotcenkov, L. B. Gulina, B. Cho, V. Brinzari and V. P. Tolstoy, Pure Appl. Chem., 2014, 86(5), 801-817.

47 G. Korotcenkov, B. K. Cho, L. B. Gulina and V. P. Tolstoy, Sens. Actuators, B, 2012, 166-167, 402-410.

48 A. A. Lobinsky, V. P. Tolstoy and L. B. Gulina, Mater. Res. Bull., 2016, 76, 229-234.

49 V. P. Tolstoy, A. A. Lobinsky, O. V. Levin and L. I. Kuklo, Mater. Lett., 2015, 139, 4-6.

50 A. A. Lobinsky, V. P. Tolstoy and L. B. Gulina, Appl. Surf. Sci., 2014, 320, 609-613.

51 X. Zheng, H. Quan, X. Li, H. He, Q. Ye, X. Xu and F. Wang, Nanoscale, 2016, 8, 17055-17063.

52 M. C. Biesinger, B. P. Payne, A. P. Grosvenor, L. W. M. Lau, A. R. Gerson, R. St and C. Smart, Appl. Surf. Sci., 2011, 257, 2717-2730.

53 X. Zou, A. Goswami and T. Asefa, J. Am. Chem. Soc., 2013, 135, 17242-17245.

54 C. Qiao, Y. Zhang, Y. Zhu, C. Cao, X. Bao and J. Xu, J. Mater. Chem. A, 2015, 3, 6878-6883.

55 V. P. Tolstoy, I. V. Chernyshova and V. A. Skryshevsky, Handbook of infrared spectroscopy of ultrathin films, John Wiley \& Sons, Inc., Hoboken, New Jersey, 2003.

56 Y. Li, L. Zhang, X. Xiang, D. Yan and F. Li, J. Mater. Chem. A, 2014, 2, 13250-13258.

57 Y. Zheng, Z. Li, J. Xu, T. Wang, X. Liu, X. Duan, Y. Ma, Y. Zhou and C. Pei, Nano Energy, 2016, 20, 94-107. 